\title{
A Fear of Not Flying
}

\author{
Laura Kenny \\ Queensland University of Technology
}

$I$

stand beside the FOR SALE sign, my back to the wind and my arms out to the sides, to increase my chances. When I rise above the house I let out a breath I didn't even realise l'd been holding.

Lately I've discovered that I can't always fly when I want to, but what scares me most is that I can't always fly when I need to either.

I was four years old the first time I flew. It was the middle of winter and we had just moved into our house. My father said the house was a duplex, which meant we had to share it, but that when the weather got warmer he was going to turn it into one big house. I thought he meant magic.

I had a new baby sister, and I thought that was magic too. Now I know that's not how babies happen. We learnt about it in school. They split up the boys and the girls before telling us, and I wondered if they told us the same thing. I wonder if they told us everything.

My mother told me to lie. When the phone rings Mum gets me to answer and say, 'I'm sorry, but my mother and father aren't home right now,' even though Mum is always home.

The bank has foreclosed on the house, which means we have to move soon.

'Where will we go? I asked.

'Somewhere,' Mum said, but I could tell she didn't know where because of the lost look in her eyes.

My father said, 'It's time to return to our roots,' which apparently means we are moving to the country.

I fly over the uprooted trees that have been piled to one side of the field, where for as long as I can remember l've picked weeds and wildflowers without discriminating. The roots look like witches' fingers. They point at the skeleton of the old people's home that is being built. 
I make daisy chains and dandelion crowns and pretend I am a princess or a goddess or just someone else.

My father says that dandelions are weeds, but I don't care. I still think they are beautiful. They're like tiny suns surrounded by lion's-teeth leaves. When the suns finish flowering and turn into moons, I blow on them to tell the time or the future or just to see the fluff flying away.

The first time I flew, I didn't know it was going to happen, so I wasn't prepared. I was lying on my bed in the dark listening to my father sing. Listening to my father sing was like trying to balance on a seesaw and not knowing if, or when, it would go up or down. Sometimes his singing meant he was happy, but more often his singing would turn into shouting, and then he would come to my room and drag me out of bed to ask, 'Who is right, me or your mother?'

It didn't take long for me to learn to say, 'You are.'

Afterwards Mum would tuck me back into bed and tell me I had done the right thing, but no matter how many times it happened it always felt wrong. That's when she started disappearing.

Mum has migraines, which means she spends whole days lying in the dark. My brother and sisters and I have to tiptoe around the house.

Mum says I'll probably have migraines because it runs in the family.

'I don't want them,' I say.

'Blame your grandmother,' Mum always says.

I used to think that there was someone under the ground who pushed all the flowers out when it was their time to bloom. My grandmother always used to say, to everyone, and to no-one in particular, 'Don't forget about me when I'm pushing up daisies.'

When I got a bit older I realised that she meant when she was dead. I didn't want her to die, but my father told me not to worry. 'That old witch will live to be a hundred.'

That night I closed my eyes and listened for my father's giant-sized footsteps on the stairs. I closed my eyes so tight and listened so hard that I didn't realise I had fallen up from the bed until my head hit the ceiling. I opened my eyes and came back down with a thump.

Sometimes Mum won't come out of the bedroom and I have to make something for dinner. I carry a plate of food to the living room, where my father sits in his recliner. Sometimes he eats it, but other times he throws the plate on the floor. Then he makes Mum get out of bed to make him some real food. 
Beyond the building site is Catfish Creek and the bend, like an elbow, where my brother and I built rafts and dug for clay and fished with rods made from sticks and string and safety pins. We never catch anything except weeds and rubbish, and I'd never tell my brother, but I'm secretly glad.

I see the suggestion of a fish under the surface and wait, knowing that nothing stays under forever. The fish breaks through the barrier and stays suspended for several seconds, supported by invisible hands, before disappearing again.

I follow the twists and turns of the creek downstream towards the centre of town. I see a jack rabbit sleeping in the sun, or dying, or already dead. It's hard to tell the difference.

I heard footsteps on the stairs, but they were soft, so it was Mum, and not my father, who opened the door. I burst into tears.

It's okay,' Mum said. 'You just fell out of bed. Did you have a bad dream?'

I nodded, but I knew it wasn't a dream and I knew I didn't just fall out of bed. Later, I was sure I could see a new crack in the ceiling.

The day my father found out about the house he started punching holes in the walls. He pulled out the built-in bed and shelves and desk in my bedroom.

'Why should the bank benefit from all my hard work?' he said.

Now I'm sleeping on my mattress on the floor.

I fly over the municipal swimming pool where I learned to swim, passing through minnows, sharks and whales in quick succession. It's empty now except for a few curled leaves in the corners, ready for winter

The second time I flew I was prepared. When my father's singing turned into shouting, I kept my eyes closed, and this time I fell right through the ceiling and into the roof space, before bursting into the night sky, where I stayed until I felt Jack Frost nibbling on my nose and my toes.

I fly over the hill where we toboggan in winter, sliding down the slippery slope and across the frozen creek to the other side.

Once the ice wasn't ready, and it cracked and I fell through the surface. I forgot how to swim. Cold hands pulled me under and I swallowed cold swampy water. 
I tried to tell Mum that I could fly, but she just said, 'That's nice,' and jiggled the baby, who was growing new teeth, on one hip while she picked up toys and threw them one-handed into the toy box.

After a while I stopped trying to tell her anything.

Some of the girls at school have brand new breasts, and they pull their shoulders back and puff out their chests like birds to show them off. They wear bras. I don't have breasts, not even the buds of breasts. Mum says not to worry, that I'll get them eventually, and that growing up is not all it's cracked up to be.

I fly over the horse-chestnut tree, with its leaves like open hands, where we collected conkers and pulled off their spiky green coats to reveal the polished nut-brown seed with their pale oval scars. We used a hammer and nail to make holes through their hearts and threaded them on kitchen string

My hands are stained green, but it doesn't matter because I am the Conker Queen.

The weather got warmer and my father started working on the house. It wasn't magic, but at least he was too busy to sing and shout. Mum sighed as if she had spent a long time under water without breathing. But he still came to my room at night.

The last few months l've been fainting at school. I'll be sitting in class and thinking hard about geometry, or the War of 1812 , or parts of speech, and I'll change size or shape, and if I stand up it feels like I'm walking on three feet of foam. l'll think 'I'm not myself,' and then I'll faint.

I never remember fainting, I just remember waking up in the principal's office. The principal's name is Mr Cox. He's mostly bald, like my father.

I fly over the four corners where there was a fire when I was a toddler. I see a collage of white snow and black smoke and red flames. I see a black river and the charred bones of the bank. I remember the fire, even though Mum says, 'That's impossible.' We were living in an upstairs apartment across the street. The window, which should have been cold and frosted with ferny spirals, feels warm when I place my hands on its surface.

I make a U-turn at the traffic lights and follow the straight line of the main street which runs parallel to the creek.

I follow a girl who looks a lot like me. She has her hair in two plaits, just like mine, and she's wearing my favourite floral dress. I wear that dress all the time. Mum has to sneak into my room at night to wash it.

I realise that the girl is me, and I wonder how it's possible to be in two places at the same time. 
A man wearing a clown mask, the kind with a bald rubber head and tufts of red growing out the sides, is following the girl.

I realise that the man is my father.

Sometimes when my father came to my room he stood and watched me pretend to sleep. Sometimes he lay down on the bed beside me. Sometimes he said, 'It's so hot in here. Why don't we take off our clothes?' except it wasn't really a question. Or 'Why don't we play a game?' Sometimes he tickled me, but it was a tickle that made me feel like I had swallowed something fluffy like a rabbit. I felt like I was choking.

By the time I turned five, I had a brand new bedroom with walls painted lilac, a purple shag carpet, and a popcorn ceiling. I was also an expert at flying.

When I wake up, Mr Cox always asks if I'm okay, and then he drives me home. Mum doesn't know how to drive, and my father is never where he's supposed to be. Mum knows where to find him, but it's easier to pretend she doesn't know where he is.

Mr Cox talks at me while he drives without expecting me to answer, which is a good thing because I'm thinking about fainting, and sometimes when I'm thinking about something I forget how to talk. Once I heard Mr Cox tell his secretary, 'That's a curious girl.'

I follow the girl and the man past the Full Gospel Tabernacle, where I went to Vacation Bible School when I was ten. The girl stops in front of the house that is almost a mansion. It used to belong to her father's family before the Depression, before they drank up the last of their money.

Every time we drive past my father says, 'That should have been my house.'

I wonder if I would have been a different person if I had grown up in that house instead. I wonder if my father would have been happier.

Last night my father came to my room. He put his penis in my mouth and held my head between his hands. I couldn't breathe and I couldn't swallow and I couldn't do anything to stop him.

Mum told me that my father wanted to name me Daisy. She thought it would limit my possibilities, so she named me Flora instead. That way I could be whatever I wanted to be. I think it's the only time my father hasn't had his way.

I stand beside the FOR SALE sign in front of house we have lived in since I was four, and wonder if I will ever fly again. 


\title{
Perhaps the Answer Can Only Ever Be 'Perhaps':
}

\author{
A Reflection
}

\begin{abstract}
A $\mathrm{m} \mathrm{I}$ a bold woman writer writing back? My instinctive response to this question is to say, 'No.' When I think of bold women writers, I think of someone like Jeanette Winterson. When asked in 1992 to name the best novel of the year, she chose her own. That's bold. I'm nothing like Winterson.
\end{abstract}

That's not entirely true. We do have something in common. We both had difficult childhoods. That's the way I usually-or used to-describe it. I tended to minimise my childhood trauma and its ongoing effects: it wasn't so bad, it's over now, it doesn't matter. When I began to study creative writing, I certainly had no intention of writing about it. However, my fiction was replete with characters who resembled me and shared many of my experiences. Yet, when I attempted to write directly about my childhood experiences, I 'lost my voice.'

As an adult survivor of childhood sexual abuse and a sufferer of Post-Traumatic Stress Disorder (PTSD), I feel compelled to tell my story, and yet I am simultaneously aware that my story cannot be 'told.' PTSD can be understood as primarily a disorder of memory, where memories of traumatic events are profoundly disorganised, poorly elaborated, and lacking context in time, place, and reference to other autobiographical memories. I often describe my memories as a shoebox full of photographs that someone has shaken and upended onto the floor. Many of my memories are attached to actual photographs, and I have to wonder if they are memories at all.

How do you write your life story when you suffer from autobiographical memory deficits? The answer-for me, and perhaps for Winterson-lies, at least in part, in autobiographical fiction.

'A Fear of Not Flying' is a work of autobiographical fiction-writing that is presented as fiction but that merges autobiographical and fictive elements. Winterson's Oranges Are Not the Only Fruit was also published as a work of fiction. It won the Whitbread Award for a first novel in 1985. Now the book is usually referred to as semi-autobiographical or an autobiographical novel. However, in the preface to the second edition Winterson writes: 'Is Oranges an autobiographical novel? No not at all and yes of course.' How is that possible? Can something be two completely opposite things at the same time? Perhaps.

Works of autobiographical fiction lie on a continuum from slightly autobiographical to highly autobiographical. If I had to quantify it, I would say that 'A Fear of Not Flying' is 95\% autobiographical and 5\% fictional. Flora's flight is a fictional construction; the things she sees, remembers, and reflects on during the flight are as true as I can make them. And yet, I am unable to write this story as a piece of non-fiction for reasons that include my autobiographical memory deficits, a tendency to self-censor, and ideas around structure, safety, and the rewriting of self. 
PTSD is characterised by the contrasting phenomena of intrusion and constriction. 'A Fear of Not Flying' can be read as a series of intrusive thoughts, memories, and dreams strung together. This is highlighted by the fragmentary nature of the narrative and the lack of clear transitions between sections. Paradoxically, the story is highly structured in that the ordering of the sections follows a strict pattern which is repeated: present tense narration of Flora's flight followed by past tense narration of the recent past mixed with present tense narration of ongoing reality, followed by past tense narration of the more distant past.

For many trauma survivors, the present and the past co-exist in the mind and it is not clear which is more real. Flora's narrative moves between the past and the present, even within the same paragraph, effectively blurring the boundaries between the two. This is not something I would be able to achieve in a work of non-fiction. The story is shaped like an incomplete circle which implies closure while simultaneously denying it.

'A Fear of Not Flying' represents my experience of dissociation-a constriction phenomenonas a coping mechanism for my childhood trauma through the metaphor of flying. I chose to explore my dissociation in this way because when I was about Flora's age and fainting regularly, I also believed I could fly. At the same time, I knew that if I told anyone that I could fly they would think I was crazy; there's a certain safety in presenting your life story as a work of fiction.

Presenting something as fiction allows me to hide. No one will know it's autobiographical, unless I tell them, which I increasingly feel the need to do in order to claim the story as my own. Even then, readers won't know which parts are 'true' and which are 'made up,' unless I tell them. This safety allows my characters to reveal things that I might not otherwise reveal.

I argue that the protagonist of a work of autobiographical fiction is liminal that she is both 'the author' and 'not the author.' Flora's name reflects her liminal status: a homophone of my name is contained within it. Flora shares my memories and experiences, but at the same time she is not exactly 'me.'

In her memoir, Why Be Happy When You Could Be Normal?, Winterson writes: 'If you continually write and read yourself as a fiction you can change what's crushing you.' Meg Jensen, a researcher and writer of autobiographical fiction, suggests that post-traumatic writers use fictive forms not only to confront and rewrite their experiences, but to also rewrite themselves.

I'm not sure how I feel about either of these claims. I know that I feel compelled to revisit the same material over and over again in my writing, but I don't know that I can change anything by doing so.

But perhaps I can. Perhaps I can rewrite myself as a bold woman writer writing back. 
What does it mean to be bold? Dictionary definitions for 'bold' as it relates to people include: 'showing a willingness to take risks': 'confident and courageous'; 'not hesitating or fearful in the face of actual or possible danger or rebuff.' At first glance, presenting my life story as a work of fiction does not seem to be bold. But perhaps it is. Perhaps the point is to tell my story in whatever form works best for me and for my experiences.

What does it mean to write back? In the simplest sense, writing back is to reply, to answer, to respond. When I write autobiographical fiction and poetry I am responding to my past. Rather than saying 'It was like this,' I can say 'Perhaps it was like this.' Or, perhaps what happened isn't the point. Perhaps, as Jensen suggests, autobiographical fiction asks why rather than what.

Am I a bold woman writer writing back?

Perhaps the answer can only ever be 'perhaps.' 